\title{
Strategies for the Purification of Membrane Proteins
}

Sinéad Marian Smith

Department of Clinical Medicine, School of Medicine, Trinity College Dublin, Ireland.

Email: smithsi@tcd.ie

\begin{abstract}
Although membrane proteins account for approximately $30 \%$ of the coding regions of all sequenced genomes and play crucial roles in many fundamental cell processes, there are relatively few membranes with known 3D structure. This is likely due to technical challenges associated with membrane protein extraction, solubilization and purification. Membrane proteins are classified based on the level of interaction with membrane lipid bilayers, with peripheral membrane proteins associating noncovalently with the membrane, and integral membrane proteins associating more strongly by means of hydrophobic interactions. Generally speaking, peripheral membrane proteins can be purified by milder techniques than integral membrane proteins, whose extraction require phospholipid bilayer disruption by detergents. Here, important criteria for strategies of membrane protein purification are addressed, with a focus on the initial stages of membrane protein solublilization, where problems are most frequently are encountered. Protocols are outlined for the successful extraction of peripheral membrane proteins, solubilization of integral membrane proteins, and detergent removal which is important not only for retaining native protein stability and biological functions, but also for the efficiency of downstream purification techniques.
\end{abstract}


Key Words: peripheral membrane protein, integral membrane protein, detergent, protein purification, protein solubilization.

\section{Introduction}

Membrane proteins are associated with the membrane of a cell or particular organelle and are generally more problematic to purify than water-soluble proteins. Membrane proteins represent approximately $30 \%$ of the open-reading frames of an organism's genome (1-4), and play crucial roles in basic cell functions including signal transduction, energy production, nutrient uptake and cell-cell communication. It is currently estimated that over $50 \%$ of marketed therapeutics are membrane protein targets $(2,3,5,6,7)$. The structural biology of membrane proteins is an ever expanding area, with the experimental determination of more than 2,000 structures to date $^{8}$. Nevertheless, purification of membrane proteins remains a challenge due to the physiochemical properties that affect their solubilization and purification in sufficient quantities for crystallisation.

Membrane proteins are classified into peripheral and integral membrane proteins, which are associated to varying degrees with the phospholipid bilayer $(\mathbf{9}, 10)$. Peripheral or extrinsic membrane proteins interact with the membrane surface noncovalently by means of electrostatic and hydrogen bonds. Peripheral membrane proteins can be recruited to the membrane during signalling events or are constitutively localised to the membrane. Integral or intrinsic membrane proteins are more strongly associated with the membrane and interact with hydrophobic moieties of the phospholipid bilayer. They contain one or more characteristic runs of apolar amino acids that span the lipid bilayer (9). Integral membrane proteins are further 
classified into Type I, which are positioned so that their $\mathrm{COOH}$-terminus is embedded in the cytosol or Type II, which are positioned with the $\mathrm{NH}_{2}$-terminus in the cytosol. Although there is no single protocol for the purification of membrane proteins, it is the initial stages of membrane protein solublilization where problems are most frequently encountered. This chapter addresses important criteria for membrane protein extraction and solubilization. The methods section describes protocols for the successful extraction of peripheral membrane proteins, solubilization of integral membrane proteins, and detergent removal which is important not only for retaining native protein stability and biological functions, but also for the efficiency of downstream purification techniques.

\subsection{Considerations for Membrane Protein Purification}

The analysis of membrane proteins represents a significant technical challenge in the field of proteomics and there are several reasons why the purification of membrane proteins is more difficult than that of water-soluble proteins. Firstly, endogenous expression of membrane proteins is relatively low and usually quite large quantities of protein are required for structural investigations. Increased protein yield may be obtained by over-expressing a recombinant membrane protein of interest in bacterial, yeast, mammalian or various cell-free expression systems $(4,11,12)$. However, differences in post-translational modifications such as glycosylation, phosphorylation and acylation can result in decreased specific activity of the recombinant protein compared to the native form. This may be overcome by using site-directed mutagenesis of the amino acids that form such modifications or by adopting changes in the conditions of the protein expression system (5). 
Secondly, integral membrane proteins are extremely hydrophobic and often require high concentrations of detergents for solubilization. Additionally, membrane proteins have the tendency to form aggregates, even in the presence of detergents, resulting in the reduction of efficiency of subsequent separation techniques (13). The choice of detergent may also affect the efficiency of down-stream protein purification procedures. For example, ion-exchange chromatography (see Chapter 12) should not be carried out in the presence of charged detergents, and hydrophobic interaction chromatography (see Chapter 24) can be problematic in the presence of all detergents (13). In such cases detergents can be removed (see Section 1.4). Furthermore, many signalling proteins are contained within lipid rafts, which are micro-domains of detergent-resistant sphingolipid and cholesterol within the plasma membrane. In such cases cholesterol-disrupting chemicals, such as nystatin of filipin, should be included in the protein purification protocol either before or during the harvesting process (14). Once solubilized, membrane proteins are often more susceptible to degradation by proteases. Thus, addition of protease inhibitors such as ethylenediamine tetraacetic acid (EDTA), which inactivates metalloproteases, or phenylmethyl sulfonyl fluoride (PMSF), which inhibits serine proteases, needs to be considered.

It is also worthwhile considering the availability of efficient functional assays to detect the integrity of the protein of interest at different stages during the purification process, for example measurement of enzymatic activity and immuno- or ligandbinding assays. Given the unique properties of individual proteins, it is usually necessary to determine appropriate assays on a case-by-case basis (13). There is no single protocol for obtaining membrane protein purification, more likely a series of methods are needed, depending on the particular needs of the investigator. 


\subsection{Peripheral Membrane Protein Extraction}

Peripheral membrane proteins can be dissociated using relatively mild techniques that break the electrostatic or hydrogen bonds between the peripheral proteins and the membrane, without total membrane disruption. Common dissociating reagents for the extraction of peripheral membrane proteins are listed in Table 1. Extractions using buffers containing high salts are useful as they decrease electrostatic interactions between proteins and charged lipids (9). Chaotropic ions disrupt hydrophobic bonds present in the membrane surface and promote the transfer of hydrophobic groups from non-polar environment to the aqueous phase (9). Usually extraction procedures employing high ionic strength $\mathrm{NaCl}$ and $\mathrm{KCl}$, alkaline or acidic buffers, and metal chelators result in a relatively distinct separation between solubilized peripheral proteins and membrane-associated integral membrane proteins (10). High $\mathrm{pH}$ causes the fractionation of peripheral membrane proteins from integral membrane proteins by disrupting sealed membrane structures without denaturing the lipid bilayer or extracting integral membrane proteins (15). The high $\mathrm{pH}$ method for extraction of peripheral membrane proteins is described in Section 3.1 of this chapter. It is worthwhile determining the effect of the buffer on any enzymatic activity the protein of interest may have, and potential interactions the buffer may have with any column matrix that will be used at later stages in the purification process. Additionally, buffer cost may need to be considered if large-scale preparations are to be carried out.

Following extraction (i.e., breaking of electrostatic and $\mathrm{H}$ bonds between peripheral protein and the membrane) in the chosen buffer for $10-30 \mathrm{~min}$, the remaining membrane bilayer and its associated integral proteins are separated by centrifugation $(30-60 \mathrm{~min}, 100,000 \mathrm{xg})$ and the released peripheral membrane proteins are recovered in the supernatant $(\mathbf{1 0}, \mathbf{1 6})$. 


\section{Insert Table 1 about here}

\subsection{Integral Membrane Protein Extraction}

In order to solubilize integral membrane proteins it is necessary to disrupt the lipid bilayer, which may be achieved with organic solvents but is more commonly accomplished using detergents. Extraction using the organic solvent N-butanol (see Section 3.2) uses a biphasic system for solubilizing proteins from membranes into dilute aqueous buffers. The low solubility of N-butanol in water, combined with its lipophilicity minimally denatures proteins (15). Detergents are amphipathic molecules that contain both hydrophobic and hydrophilic moieties and form micelles in water. A micelle is a cluster of detergent molecules in which the hydrophilic head moieties face outward. Detergents solubilize proteins by binding to the hydrophobic parts of the protein on one side and interacting with the aqueous parts on the other side (8). The detergent of choice should sufficiently solubilize the membrane protein without irreversibly denaturing it. Detergents can be ionic, non-ionic or zwitterionic. A list of commonly used detergents for extraction of integral membrane proteins is shown in Table 2. Selection of a particular detergent depends on the properties of the protein of interest and the given aims of subsequent experiments involving the purified protein. If there is little information in the literature on the purification of similar proteins, or if one is purifying a particular protein for the first time, it is often necessary to screen a number of detergents in order to optimise protein solubilization. Membrane aliquots should be incubated with various concentrations of commonly used detergents and incubation time, buffer concentration, salt solutions and temperature conditions necessary for optimal solublization should be determined. A 
protocol describing detergent screening for membrane protein purification for analysis by mass spectroscopy has recently been described (3).

\section{Insert Table 2 about here}

When screening potential detergents, it is important to be aware of the unique critical micelle concentration (CMC), which is the concentration of free detergent at which the transition from disperse detergent molecules to a micellar structure occurs (16). Since solubilization corresponds to the removal of the protein from the membrane into the detergent micelle, the $\mathrm{CMC}$ is the minimal concentration of detergent necessary to form the required micellar structure for protein extraction (16). CMC values, some of which are listed in Table 2, vary between different detergents, but are usually available from the detergent manufacturer.

Additional considerations when choosing detergents include evaluating the effects of a given detergent on the structural and functional properties of the protein of interest. The effects of detergents on the protein stability may be checked during preliminary screens using different detergents. More recently developed detergents, such as maltose-neopentyl glycol (MNG) amphiphiles (17), non-ionic amphipols (NAPols) (18) and steroid-based facial amphiphiles (19) have shown advantages over conventional detergents in terms of protein stability and enhancing the likelihood of obtaining crystals. The compatibility of the chosen detergent with subsequent purification steps should also be considered as certain detergents may affect the efficiency of the downstream chromatographic technique. For example, charged detergents may cause problems using assays based on charge difference, such as ion 
exchange chromatography (see Chapter 2), and lectin chromatography which may be used to affinity purify subsets of glycoproteins is especially sensitive to high concentrations of a variety of detergents $(7,8)$. It is often necessary to remove or replace detergents to overcome these problems, thus the ease at which excess detergent can be removed from the solubilized protein fraction should be considered (see Section 1.4).

When solubilizing integral membrane proteins, buffered stock solutions at a physiological $\mathrm{pH}$ environment should be prepared containing the membrane preparation, detergent and protease inhibitors, such as EDTA, EGTA and/or PMSF (16). Membrane preparations are used at a final protein concentration of $1-5 \mathrm{mg} / \mathrm{mL}$ and are solubilized by detergent concentrations of $0.1-5 \%(\mathrm{v} / \mathrm{v})(\mathbf{1 0}, 16)$. The mixture should be stirred gently for 1 hour at room temperature or $4{ }^{\circ} \mathrm{C}$, followed by centrifugation for 1 hour at $100,000 \mathrm{x} g$ at $4^{\circ} \mathrm{C}$. Generally speaking, retention of a membrane protein in the supernatant following centrifugation for $60 \mathrm{~min}$ at 100,000 $\mathrm{x}$ $\mathrm{g}$ after solubilizaion defines this protein as soluble (10). The pellet may subsequently be washed to remove residual detergent and finally resuspended in the appropriate buffer (16). Protein recovery and activity should be investigated in both the pellet and supernatant at this stage. The procedure for solubilizing membrane proteins using the non-ionic detergent Triton $\mathrm{X}-100$ is outlined in Section 3.3.

\subsection{Removal of Detergents from Membrane Protein Fractions}

The high detergent concentrations that are often required during the initial extraction of integral membrane proteins could potentially affect the stability and subsequent analysis of the isolated membrane proteins, therefore excess detergent should be 
removed or exchanged for an alternative detergent prior to subsequent purification procedures. Examples of methods used to remove or exchange detergents are listed in Table 3. The choice of technique depends on the unique properties of the detergent used and the concentration range of the protein fraction.

\section{Insert Table 3 about here}

Successful detergent exchange or removal can be achieved using various chromatographic supports, followed by extensive washing with the desired buffer, containing the new detergent if necessary (9). Alternatively dialysis can be carried out to facilitate detergent exchange or removal. The efficiency of dialysis depends on the $\mathrm{CMC}$ and micelle molecular weight, which is determined by the aggregation number of detergent molecules (20). Most detergents with linear alkyl hydrophobic groups (e.g. Triton X-100) have a high micelle molecular weight value and do not pass through dialysis membranes (9). Detergents with a low micelle molecular weight and high CMC (e.g. bile acids and their derivatives) can be removed by dialysis (9). A protocol for dialysis is described in Section 3.4 of this chapter. Detergent removal by means of chromatographic supports (see Section 3.5) is relatively work-intensive but is a more rapid procedure than dialysis so can be advantageous in cases where protein stability is an issue.

Following initial extraction of membrane proteins, solubilization using detergent, and detergent removal or exchange, membrane proteins can then be purified to homogeneity using a variety of protein purification techniques, depending on the particular needs of the investigator and the given properties and abundance of the 
protein of interest. Because there is no single procedure to characterize membrane proteins, the key importance of membrane purification lies with the initial extraction and solubilization steps, in order to generate a high yield of pure protein in its native biologically active state. The methods section of this chapter outlines examples of techniques used during the important initial stages of membrane protein purification.

\section{Materials}

2.1 Fractionation of Peripheral and Integral Membrane Proteins using High pH

1. High pH buffer: $100 \mathrm{~m} M \mathrm{Na}_{2} \mathrm{CO}_{3}, \mathrm{pH} 11.3$

2. Dounce homogeniser e.g. Potter-Elvehjem PTFE pestle and glass tube (SigmaAldrich)

3. Ultracentrifuge e.g. Thermo Scientific Sorvall WX

\subsection{Extraction of Membrane Proteins using Butanol}

1. N-butanol

2. Cooled bench top centrifuge e.g. Eppendorf centrifuge 5417R

\subsection{Extraction of Membrane Proteins using Triton X-100}

1. TE buffer: $10 \mathrm{~m} M$ Tris-HCl, $2 \mathrm{mM}$ EDTA

2. $2 \%$ Triton $\mathrm{X}-100$ in phosphate buffered saline (PBS) (see Note 1)

3. Ultracentrifuge e.g. Thermo Scientific Sorvall WX

\subsection{Removal of Non-ionic Detergents by Detergent-adsorption Chromatography}

1. Columns with a bed volume of approx. $5 \mathrm{~mL}$ (e.g. Econo-column, Bio-Rad) 
2. Commercially available detergent absorption matrix, (e.g. Bio-Beads SM-2, BioRad, see Note 2)

3. Blocking buffer: $0.1 \%(\mathrm{w} / \mathrm{v})$ bovine serum albumin in $50 \mathrm{~m} M$ Tris- $\mathrm{HCl}, \mathrm{pH} 7.4$, $0.15 \mathrm{M} \mathrm{NaCl}$ (see Note 3)

4. Washing buffer: $50 \mathrm{~m} M$ Tris-HCl, $\mathrm{pH} 7.4,0.15 \mathrm{M} \mathrm{NaCl}$

\subsection{Removal of Detergent with Low Micelle Size and High CMC by Dialysis}

1. Dialysis tubing with a molecular weight cutoff of approx. 10,000 Da

2. Wash buffer: $100 \mathrm{~m} M \mathrm{NaHCO}_{3}, 50 \mathrm{~m} M$ EDTA

3. Dialysis buffer: $20 \mathrm{~m} M$ Tris-HCl, $\mathrm{pH} 7.4,0.15 \mathrm{M} \mathrm{NaCl}$

\section{Methods}

\subsection{Fractionation of Peripheral and Integral Membrane Proteins using High pH}

1. Resuspend the membrane fraction (see Note 4) at a concentration of $<2 \mathrm{mg} / \mathrm{mL}$ in high $\mathrm{pH}$ buffer (see Notes 5 and 6).

2. Homogenise the suspension in a dounce homogeniser using 6-8 strokes.

3. Maintain at $4^{\circ} \mathrm{C}$ for $30 \mathrm{~min}$. Mix by vortexing 3 times during this period.

4. Pellet the membrane fraction by centrifugation for $60 \mathrm{~min}$ at $100,000 \mathrm{xg}$ at $4^{\circ} \mathrm{C}$ and transfer the supernatant, which contains the peripheral membrane proteins, into a fresh tube and assay for protein (see Note 7).

\subsection{Extraction of Membrane Proteins using Butanol}

1. Add an equal volume of N-butanol to the membrane fraction (see Note 4), and maintain at $4^{\circ} \mathrm{C}$. 
2. Centrifuge at $500 \mathrm{xg}$ at $4^{\circ} \mathrm{C}$ for $10 \mathrm{~min}$ to separate the mixture into an upper phase containing butanol and membrane lipids and a lower aqueous phase containing solubilized proteins. Lipid rich material is localised to the interface.

3. Separate the upper and lower aqueous phases into separate tubes.

4. Dialyze the aqueous phase against a large volume of water or suitable buffer.

5. Assay the dialysed aqueous phase for protein (see Note 8).

\subsection{Extraction of Membrane Proteins using Triton $X-100$}

1. Resuspend cells in TE buffer at a concentration of $1 \times 10^{7}$ cells $/ \mathrm{mL}$.

2. Centrifuge the cells at 40,000 x g for $10 \mathrm{~min}$. Remove the supernatant and add fresh TE.

3. Repeat this step and resuspend the cells in approximately $1 \mathrm{~mL}$ of TE.

4. Add cells dropwise to the $2 \%$ Triton X-100 while stirring (see Note 9).

5. Allow to solubilize for $30 \mathrm{~min}$ at $4{ }^{\circ} \mathrm{C}$.

6. Centrifuge at $100,000 \mathrm{x}$ g for $30 \mathrm{~min}$ at $4^{\circ} \mathrm{C}$.

7. Transfer the supernatant to a fresh tube and assay for protein (see Note 10).

\subsection{Removal of Non-ionic Detergents by Detergent-adsorption Chromatography}

1. Before starting, ensure that the protein fraction containing the non-ionic detergent (e.g. Triton $X-100)$ has a concentration of $>1 \mathrm{mg} / \mathrm{mL}$ (see Note 11) and that the molecular weight of the protein to be recovered is large enough to avoid entrapment in the pores of the affinity matrix.

2. Apply distilled water to the column matrix, followed by blocking buffer. Next, apply washing buffer to the column and repeat wash step.

3. Transfer the protein fraction to the column matrix (see Note 12). 
4. Collect $0.5-1 \mathrm{~mL}$ fractions and assay for protein.

\subsection{Removal of Detergent with Low Micelle Size and High CMC by Dialysis}

1. Prepare the dialysis tubing by boiling a section in washing buffer for $10 \mathrm{~min}$ (see

Note 13). Then boil the dialysis tubing in distilled water for $10 \mathrm{~min}$, followed by washing thoroughly in distilled water.

2. Transfer the solubilized membrane protein fraction into the dialysis tubing (see Note 14) which is securely closed at one end by either tying a double-knot in the tubing or securing it with a plastic clamp (see Note 15)

3. Remove air bubbles and seal the dialysis tubing, allowing for a volume increase during dialysis. Check the integrity of the seal to ensure no leakage occurs.

4. Place the tubing in a beaker containing a large external volume (approx. $5 \mathrm{~L}$ ) of the appropriate buffer. Dialyze with gentle stirring at $4{ }^{\circ} \mathrm{C}$. Change the external buffer regularly.

5. When the dialysis is finished, remove the dialysis tubing and wash the outside. Hold the tubing and carefully remove the upper clamp. Using a Pasteur pipette, transfer the protein fraction to a new tube (see Note 16).

\section{Notes}

1. Make a stock solution of $20 \%$ Triton X-100 by weighing $2 \mathrm{~g}$ Triton X-100 and adding PBS up to $10 \mathrm{~mL}$ and stirring gently until fully dissolved. Store the stock solution at $4{ }^{\circ} \mathrm{C}$.

2. Bio-Beads are macroporous polystyrene beads and have a high surface area that adsorbs organics with a molecular weight of $<2000$ from aqueous solution. They may be used to remove Triton X-100 from protein fractions. Due to the presence of 
linear alkyl hydrophobic groups, Triton X-100 has a high micelle molecular weight value and does not pass through dialysis membranes. Detergents with a low micelle molecular weight and high CMC (e.g. bile acids and their derivatives) can be removed by dialysis (see Section 3.5).

3. Bovine serum albumin is used as a bulk carrier protein to saturate non-specific protein binding sites and minimise protein loss during this procedure.

4. The starting material depends on the source from which the membrane proteins are being purified. Membrane proteins can be successfully isolated from plant and animal tissues or cell cultures, bacteria, yeast and fungi. Animal tissues can be broken easily with a mixer or blender. Due to the presence of robust cell walls, unicellular organisms like yeast or bacteria and plant cells are more difficult to disrupt. Different techniques for breaking down cell walls include glass bead milling, grinding mills, homogenization, ultrasonication, osmotic shock, repeat freeze thawing and enzymatic lysis (13). If possible the protein should be prepared from sources where it is in high abundance, as a certain amount of protein may be lost during the purification process. The starting material can be enriched if the target protein is known to be associated with the plasma membrane, mitochondria or nucleus. During initial steps of membrane protein isolation, cytosolic proteins can be removed to obtain an enriched preparation of membranes containing the protein of interest. Soluble cytoplasmic proteins are extracted by cell disruption in a neutral $\mathrm{pH}$, isotonic and detergent-free buffer (10), followed by differential centrifugation or purification using sucrose gradient centrifugation.

5. The $\mathrm{pH}$ of the working buffer should be tested following addition of any protease inhibitors, as addition of such components may alter the final $\mathrm{pH}$ of the buffer. 
6. It is worthwhile determining the effect of the high $\mathrm{pH}$ buffer on any enzymatic activity the protein of interest may have, and considering potential interactions the buffer may have with any column matrix that will be used at later stages in the purification process.

7. A suitable protein concentration assay should be considered. Options include measuring ultra-violet absorbance at $280 \mathrm{~nm}$, or using one of several commercially available dye-binding assays, such as the Bradford assay, the bicinchonic acid (BCA) assay or other assays (see Chapter 13).

8. It is worthwhile to keep the butanol phase for protein assays as it may contain extremely hydrophobic proteins that are difficult to solubilize.

9. The effect of the Triton X-100 solubilization procedure on the structural and functional properties of the protein of interest should be evaluated during preliminary screening experiments. In order to maintain catalytic activity, the membrane protein should be dissolved under optimal conditions for stability at a detergent/protein ratio that is not much above the minimal detergent/protein ratio required for solubilization (13). Additionally, proteins are more susceptible to protease attack following solubilization with detergents so protease inhibitors are necessary to prevent protein degradation. Premixed cocktails of commonly used protease inhibitors are now available commercially from a variety of companies including Roche, Sigma-Aldrich and Pierce. It is recommended to carry out purification procedures at $4^{\circ} \mathrm{C}$ in order to minimise proteolysis (see Chapter 4). Additionally, the effects of Triton X-100 on subsequent purification techniques should be evaluated. Replenish protein stabilizing additives or protease inhibitors if they are removed or inactivated at any stage in the experiment, for example EDTA is removed by hydroxyapatite chromatography (13). 
If possible minimise any purification steps that add new detergents or alter the original detergent/lipid ratio.

10. Due to the presence of aromatic groups, Triton X-100 has substantial UV absorbance at $280 \mathrm{~nm}$, thus an alternative protein concentration assay should be carried out. For the same reason, Triton X-100 is not suitable for subsequent purification steps involving column chromatography with UV monitoring of the fractions. As an alternative, bile salts and their derivatives including CHAPS and CHAPSO can be used for solubilization.

11. A high concentration is necessary to allow for any loss of protein during the procedure.

12. Use washing buffer to dissolve the protein fraction for optimum detergent binding. 13. As dialysis tubing is susceptible to cellulolytic micro-organisms, gloves should be worn when handling the tubing.

14. A small funnel may be used to aid transfer of the protein fraction into the dialysis tubing

15. Prior to transferring the protein fraction into the dialysis tubing, the integrity of the membrane and clamp/knot can be tested by applying water or buffer and checking the tubing for leaks.

16. Avoid losing dialyzed samples by carefully opening the tubing over a larger glass beaker to collect any accidental spillage.

\section{References}

[1] Wallin, E., and von Heijne, G. (1998) Genome-wide analysis of integral membrane proteins from eubacterial, archaean, and eukaryotic organisms, Protein Sci 7, 1029-1038. 
[2] Souda, P., Ryan, C. M., Cramer, W. A., and Whitelegge, J. (2011) Profiling of integral membrane proteins and their post translational modifications using high-resolution mass spectrometry, Methods 55, 330-336.

[3] Laganowsky, A., Reading, E., Hopper, J. T., and Robinson, C. V. (2013) Mass spectrometry of intact membrane protein complexes, Nat Protoc 8, 639-651.

[4] Zorman, S., Botte, M., Jiang, Q., Collinson, I., and Schaffitzel, C. (2015) Advances and challenges of membrane-protein complex production, Curr Opin Struct Biol 32, 123-130.

[5] Chiu, M. L. (2012) Introduction to membrane proteins, Curr Protoc Protein Sci Chapter 29, Unit 2921.

[6] Mohanty, A. K., and Wiener, M. C. (2004) Membrane protein expression and production: effects of polyhistidine tag length and position, Protein Expr Purif $33,311-325$.

[7] Gordon, E., Horsefield, R., Swarts, H. G., de Pont, J. J., Neutze, R., and Snijder, A. (2008) Effective high-throughput overproduction of membrane proteins in Escherichia coli, Protein Expr Purif 62, 1-8.

[8] Stansfeld, P. J., Goose, J. E., Caffrey, M., Carpenter, E. P., Parker, J. L., Newstead, S., and Sansom, M. S. (2015) MemProtMD: Automated Insertion of Membrane Protein Structures into Explicit Lipid Membranes, Structure 23, $1350-1361$.

[9] Ahmed, H. (2005) Principles and Reactions of Protein Extraction, Purification and Characterization, CRC Press, Boca Raton, Florida.

[10] Ohlendieck, K. (1996) Extraction of Membrane Proteins, In Protein Purification Protocols (Doonan, S., Ed.), Humana Press Inc., Totowa, NJ. 
[11] Zheng, X., Dong, S., Zheng, J., Li, D., Li, F., and Luo, Z. (2014) Expression, stabilization and purification of membrane proteins via diverse protein synthesis systems and detergents involving cell-free associated with selfassembly peptide surfactants, Biotechnol Adv 32, 564-574.

[12] Routledge, S. J., Mikaliunaite, L., Patel, A., Clare, M., Cartwright, S. P., Bawa, Z., Wilks, M. D., Low, F., Hardy, D., Rothnie, A. J., and Bill, R. M. (2015) The synthesis of recombinant membrane proteins in yeast for structural studies, Methods.

[13] Von Jagow, G., Link, T., and Schager, H. (1994) Purification strategies for membrane proteins, In A practical guide to membrane protein purification (Von Jagow, G., and Schager, H., Eds.), Academic Press, San Diego, CA.

[14] Orsburn, B. C., Stockwin, L. H., and Newton, D. L. (2011) Challenges in plasma membrane phosphoproteomics, Expert Rev Proteomics 8, 483-494.

[15] Rosenberg, I. M. (2005) Protein Analysis and Purification: Benchtop Techniques, 2nd. ed., Springer.

[16] Schimerlik, M. I. (2001) Overview of membrane protein solubilization, Curr Protoc Neurosci Chapter 5, Unit 59.

[17] Chae, P. S., Rasmussen, S. G., Rana, R. R., Gotfryd, K., Chandra, R., Goren, M. A., Kruse, A. C., Nurva, S., Loland, C. J., Pierre, Y., Drew, D., Popot, J. L., Picot, D., Fox, B. G., Guan, L., Gether, U., Byrne, B., Kobilka, B., and Gellman, S. H. (2010) Maltose-neopentyl glycol (MNG) amphiphiles for solubilization, stabilization and crystallization of membrane proteins, Nat Methods 7, 1003-1008.

[18] Bazzacco, P., Sharma, K. S., Durand, G., Giusti, F., Ebel, C., Popot, J. L., and Pucci, B. (2009) Trapping and stabilization of integral membrane proteins by 
hydrophobically grafted glucose-based telomers, Biomacromolecules 10 , 3317-3326.

[19] Lee, S. C., Bennett, B. C., Hong, W. X., Fu, Y., Baker, K. A., Marcoux, J., Robinson, C. V., Ward, A. B., Halpert, J. R., Stevens, R. C., Stout, C. D., Yeager, M. J., and Zhang, Q. (2013) Steroid-based facial amphiphiles for stabilization and crystallization of membrane proteins, Proceedings of the National Academy of Sciences of the United States of America 110, E12031211.

[20] Ohlendieck, K. (1996) Removal of Detergent from Protein Fractions, In Protein Purification Protocols (Doonan, S., Ed.), Humana Press Inc, Totowa, NJ. 
Treatment Type

Acidic buffers

Alkaline buffers

Chaotropic ions

Denaturing agents

Metal chelators

Salt solutions/high ionic strength

\section{Example}

$\mathrm{pH} 3.0-5.0$

pH 8.0 - 12.0 (e.g. $100 \mathrm{~m} M \mathrm{Na}_{2} \mathrm{CO}_{3}, \mathrm{pH}$

11.3, see Section 3.1)

$\mathrm{I}^{-}, \mathrm{ClO}_{4}^{-}, \mathrm{SCN}^{-}$

$8 M$ urea or $6 M$ guanidine hydrochloride

$10 \mathrm{~m} M$ EDTA or EGTA

$1 M \mathrm{NaCl}$ or $\mathrm{KCl}$

Table 1: Treatments for the Extraction of Peripheral Membrane Proteins 


\begin{tabular}{|c|c|c|c|}
\hline $\begin{array}{l}\text { Detergent } \\
\text { Type }\end{array}$ & Name & $\begin{array}{l}\text { Alternative Chemical } \\
\text { Name }\end{array}$ & $\mathrm{CMC}^{*}(\mathrm{~m} M)$ \\
\hline \multirow[t]{2}{*}{ Ionic } & CTAB & $\begin{array}{l}\text { Cetyltrimethylammonium } \\
\text { bromide }\end{array}$ & 1.0 \\
\hline & $\begin{array}{l}\text { Sodium cholate } \\
\text { Sodium deoxycholate }\end{array}$ & & $\begin{array}{l}\sim 10 \\
\sim 2\end{array}$ \\
\hline \multirow[t]{4}{*}{ Non-ionic } & Big Chap & $\begin{array}{l}N, N \text {-bis }\left(3 \text { - }^{-}\right. \\
\text {gluconamidopropyl)cholami } \\
\text { de }\end{array}$ & 3.4 \\
\hline & $\mathrm{C}_{12} \mathrm{E}_{8}$ & $\begin{array}{l}\text { Octaethylene glycol } \\
\text { monododecyl ether }\end{array}$ & $<0.1$ \\
\hline & Triton X-100 & $\begin{array}{l}\text { Nonaethylene glycol } \\
\text { octylphenol ether }\end{array}$ & 0.3 \\
\hline & Triton X-114 & $\begin{array}{l}\text { tert-octylphenoxypoly } \\
\text { (ethoxyethanol) }\end{array}$ & 0.2 \\
\hline \multirow[t]{3}{*}{ Zwitterionic } & CHAPS & $\begin{array}{l}\text { 3-[(3-cholamidopropyl) } \\
\text { dimethylammonio]-1- } \\
\text { propanesulfonate }\end{array}$ & $3-10$ \\
\hline & CHAPSO & $\begin{array}{l}\text { 3-[(3-cholamidopropyl) } \\
\text { dimethylammonio]-2- } \\
\text { hydroxypropane-1-sulfonate }\end{array}$ & $4-8$ \\
\hline & LDAO & $\begin{array}{l}\text { Dodecyldimethylamine } \\
\text { oxide }\end{array}$ & $\sim 1$ \\
\hline
\end{tabular}

\section{Table 2: Detergents used for extracting integral membrane proteins}

*CMC: critical micelle concentration 


\begin{tabular}{ll}
\hline Technique & Reagent \\
\hline Affinity chromatography & Ligand immobilized sepharose \\
Equlibrium dialysis & Appropriate buffer or water \\
Gel permeation chromatography & Sephadex G-25 (GE Healthcare) \\
Hydrophobic interaction chromatography & Bio-Beads SM-2 (Bio-Rad) \\
Ion-exchange chromatography & Dowex 1-X2 (Sigma Aldrich) \\
Precipitation & Acetone \\
Ultrafiltration & High molecular weight cut off membrane \\
\hline
\end{tabular}

Table 3: Commonly used techniques for detergent removal/exchange 